\title{
Effective and equivalent dose minimization for personnel in PET procedures: how far are we from the goal?
}

\author{
M. Lecchi ${ }^{1,2} \cdot$ S. Malaspina ${ }^{1,2} \cdot$ A. Del Sole ${ }^{1,2}$
}

Published online: 14 September 2016

(C) Springer-Verlag Berlin Heidelberg 2016

Radiation dose limitation in patients undergoing nuclear medicine procedures is accomplished through adherence to the principles of justification and optimization, while radiation doses to operators are controlled mainly by reducing exposure times, using shielding, and increasing the distance from the source. In both cases, however, a key role in dose management can also be played by innovative technologies, making this an important issue not only for nuclear medicine specialists, medical physicists, and technologists, but also for biomedical engineers and for industry [1-3]. ${ }^{1}$

Whereas the quest to achieve effective dose optimization for patients, in accordance with the ALARA principle, is currently the focus of intensive research and technological development activity, the need to develop and implement new devices to reduce operator exposure to ionizing radiation seems to be a secondary concern. Twenty years ago, for the concerns

\footnotetext{
${ }^{1}$ The decay of positron emitters produces four times the amount of energy in photons than the decay of technetium- $99 \mathrm{~m}$ does. The gamma ray constant of $511 \mathrm{keV}$ annihilation photons is $1.81 \mu \mathrm{Sv} / \mathrm{h}$ per MBq at $30 \mathrm{~cm}$ from an unshielded point source, while that of $140 \mathrm{keV}$ photons is $0.26 \mu \mathrm{Sv} / \mathrm{h}$ per $\mathrm{MBq}$ at $30 \mathrm{~cm}$ from an unshielded point source. Whereas the half-value layer (HVL) of $140 \mathrm{keV}$ photons consists of approximately $0.03 \mathrm{~cm}$ of lead, $4.5 \mathrm{~cm}$ of water and $4000 \mathrm{~cm}$ of air, the HVL of $511 \mathrm{keV}$ photons comprises approximately $0.6 \mathrm{~cm}$ of lead, $7.5 \mathrm{~cm}$ of water, and $6500 \mathrm{~cm}$ of air. For the sake of comparison, the dose rate due to a given technetium- 99 m activity corresponds to $14 \%$ of that delivered by the same amount of fluorine-18 activity.
}

A. Del Sole

angelo.delsole@unimi.it

1 Department of Health Sciences, University of Milan, Via Antonio di Rudinì, 8, 20142 Milan, Italy

2 Nuclear Medicine Unit, Department of Diagnostic Services, ASST Santi Paolo e Carlo, Milan, Italy raised by the radiation energy of the highly penetrating $511 \mathrm{keV}$ annihilation photons, the first study of personnel dosimetry in positron emission tomography (PET) found that the effective radiation doses to technologists in PET centres (mostly carrying out ${ }^{18} \mathrm{~F}$-FDG studies) were within recommended occupational radiation protection guidelines [4], and since then, comparatively little attention has been paid to the problem of operator exposure.

However, in view of the now constantly increasing number of PET procedures being carried out in centres around the world, the use of positron emitters is becoming a real and a growing occupational concern. In this regard, it needs to be appreciated, in particular by those working in nuclear medicine on a day to day basis, that PET requires different radiation protection strategies from those usually adopted in general nuclear medicine, for reducing both the effective and equivalent dose to the extremities below the acceptable levels.

Despite the use of routine precautionary measures, including the use of dedicated hot-cells, occupational doses in PET are higher than they need to be in order to obtain good quality examinations. The physical properties of positron emitting radiopharmaceuticals and the optimization of patient doses are both factors that, in addition to the greater number of PET studies now performed, can result in unnecessarily high occupational doses if adequate radiation protection operational procedures for working with positron emitting radionuclides are not envisaged, explained and rigorously adopted across all PET units, in accordance with local conditions.

There are in fact three sources of exposure that contribute to the total personnel exposure for a given PET study, keeping in mind that their burden can be shared among different operators: indeed, exposure occurs during i) the patient undergoing the procedure, ii) the vial during the dispensing of the radiopharmaceutical, and iii) the syringe during the injection of the radiopharmaceutical. 
By considering the three sources above, one should consider that one of the main variables influencing the effective dose, both to staff and to the patient, is the amount of activity handled during the dispensing procedures and eventually administered to the patient. Such amounts have been found to be highly heterogeneous [5], which suggests that failure to optimize PET procedures is a major cause for high occupational doses. Therefore, optimization of the amount of activity administered to the patient is the first step allowing reducing both the effective and the equivalent dose to staff members by a factor of at least two.

Furthermore, it is necessary to make provision for appropriate training, in order to make operators aware of the importance of the three pillars of radiation protection (i.e. reduction of exposure time, shielding, and distance from the source) and thus able to limit the effective and equivalent doses. In fact, it is remarkable that in optimized operational conditions, thus following well defined procedures, it is possible to achieve an operator effective dose of approximately 5-6 $\mu \mathrm{Sv}$ per scanned patient, or less $[6,7]$. It has indeed been reported that under optimal circumstances a total average effective dose per member of staff as low as $0.7 \mathrm{mSv} /$ year and an average dose of $4.91 \mu \mathrm{Sv} /$ day can be achieved in a fully operational PET unit [8].

Having established that the occupational effective dose from exposure to radioactive sources (the vial, the syringe, and the patient himself) can be kept below the limit of $20 \mathrm{mSv} /$ year, there remains the issue of the equivalent dose to the eye lenses and to the extremities. Since the dose to the lenses is closely related to, and of the same magnitude as, the effective dose [9], the annual limit on the dose to the lenses is very unlikely to be exceeded among nuclear medicine staff $[10,11]$.

Whereas the effective dose can easily be measured using a personal dose meter, the equivalent dose, usually measured by ring dose meters worn on the proximal phalanx of the index finger, is very difficult to assess accurately. During vial and syringe handling, the occupational equivalent dose to the fingertip of staff responsible for preparing and dispensing radiopharmaceuticals may vary depending on the procedures used [12]. In particular, it has been demonstrated that the dispensing modality used, and even the way in which the operator injecting the radiopharmaceutical holds the syringe, may result in different equivalent doses to each finger among the operators [13]. Moreover, the measures of absorbed dose at the base of a finger, provided by a ring dose meter, may not be representative of the effective dose at the fingertip, i.e. the most exposed area. It should be noted that, as a rule, fingertip doses are not measured, but rather estimated by applying a factor of 2-6 to the readings of the thermoluminescent (TLD) ring dose meter, in order to take into account the distance between the ring and the fingertip $[14,15]$.

In a study that used high-sensitivity TLD detectors placed on the fingertips of both hands and attached at the level of eye lenses and thyroid to assess equivalent doses to staff members, the highest dose was measured during the administration of ${ }^{18} \mathrm{~F}$-FDG to the patients and during the preparation of ${ }^{18} \mathrm{~F}$ FDG, the most exposed body parts being the tips of the thumb, index, and middle fingers [11]. The data from this study suggest that in a PET centre running $1500{ }^{18} \mathrm{~F}$-FDG scans per year, and using approximately $200 \mathrm{MBq}$ per patient, the annual occupational equivalent dose to the fingers due to the fractionation of the radiopharmaceutical in a dedicated hot cell would not exceed $100 \mathrm{mSv}$. For the personnel administering the activity to the patient the estimated annual dose to the fingertips would not exceed $200 \mathrm{mSv}$. Such annual equivalent doses are within the dose limits for the skin $(500 \mathrm{mSv})$.

However, according to the results of the EURORADOS report, which were based on a survey in 17 PET centres, each with a workload of 1000 patients per year and a uniform dose for each procedure, the annual dose limit to the extremities would be surpassed by $20 \%$ of the operators administering the activity, $400 \mathrm{MBq}$ per patient, and by $40 \%$ of the staff members in charge of the fractionation of ${ }^{18} \mathrm{~F}-\mathrm{FDG}, 500 \mathrm{MBq}$ per fraction. Also, other authors have reported cases of workers performing PET scanning procedures in whom the annual dose limit may exceed the limit of $500 \mathrm{mSv} /$ year [13, 16-19].

The differences in the literature data are due to differences, between the various reports, in the doses handled and in the way in which the workload is shared. It appears that the observation of excess in equivalent doses reported by EURORADOS may depend upon excessive administered activity, as well as scarce training or inadequate management/ rotation of the personnel.

Many of the above-mentioned problems concerning operator effective and equivalent doses, but also effective doses to patients, can be addressed and possibly minimized by exploiting the shielded and semi-automated fractionation-injection devices that have been developed over the past 10 years. Although these instruments are still not widely used, mainly due to the investment required and the running costs involved, they mark a turning point in the performance of PET procedures, allowing a reduction of the effective and equivalent dose to staff.

Use of any of these devices can reduce the effective dose for personnel to just $10-50 \%$ of the dose associated with manual fractionation and injection [20, 21]. By halving the effective dose for personnel during the tracer injection phase, an overall dose reduction of approximately $25 \%$ per assisted patient can be achieved. Concurrently, the equivalent dose to the extremities, i.e. fingertips, can be reduced by more than $95 \%[22,23]$ compared with the equivalent dose associated with manual administration.

Another important issue concerns the optimization of the activity administered to patients. The use of an automatic device for personalizing injections of very precise doses in 
relation to patient's body weight is likely to translate in a reduction in the effective dose received by the operators, but also into less radiation exposure for patients, meeting their expectations [24].

At our institution, where patients are administered 3.7 MBq/kg body weight, the introduction of an automated fractionation-injection device has allowed an immediate marked decrease in the extremity dose to technologists, responsible for fractionation and subject to post-injection exposure, and to physicians responsible for performing injections. The extremity dose to the technologists working in PET, and using the automated device, dropped from twice to half that recorded for the technologists working with conventional nuclear medicine and performing manual fraction in a dedicated hot-cell, i.e. from 80 to $20 \mu \mathrm{Sv} / \mathrm{GBq}$; at the same time, the extremity dose to physicians involved in the radiopharmaceutical injections fell from about $65 \mu \mathrm{Sv} / \mathrm{GBq}$, the level associated with manual injection, to a current level that is below our TLD ring dosimeter's minimum measurable cumulative monthly dose $(20 \mu \mathrm{Sv})$, approximately $1 \mu \mathrm{Sv} / \mathrm{GBq}$ (unpublished data).

\section{Conclusions}

Low occupational doses can be achieved when a PET unit is organized in such a way that the operator dose per examined patient is shared among different professionals, e.g. technologists, physicians, and nurses, compatibly with the organization of the single PET centre and the specific roles of the different staff members, determined by local regulations. For this reason, systematic rotation and workload sharing of the personnel through careful planning would reduce the doses according to the number of operators involved and neutralize the risk of excess equivalent dose to operators. Adequate training in the handling of radioactive sources during radiopharmaceutical dispensing and injection and optimization of the administered dose can reduce both the occupational effective dose and the occupational equivalent dose for each single scan. Furthermore, personalization of the administered dose, rather than the use of a fixed dose, would reduce not only the patient exposure, satisfying the principle of optimization, but also the operator doses.

Since several studies have shown that the equivalent dose to the fingertips may easily exceed the legal limit for manual procedures (i.e. $500 \mathrm{mSv} / \mathrm{year}$ ), two strategies should be considered: first, the use of tiny TLD dose meters on the fingertips to ensure accurate measurement, at least during training and for periodic checks, and second, the implementation, in PET centres, of automated dispensing and injection devices. We believe that the latter solution may also make it possible to reduce the number of operators involved in PET procedures, bringing economic savings and, most important, reducing unnecessary exposure, which in some cases exceeds the legal limits.

\section{Compliance with ethical standards}

Conflict of interest All authors declare that they have no conflict of interest.

Ethical approval This article does not contain any studies with patients or animals performed by any of the authors.

Funding A.D.S. is the recipient of funds from Bayer Medical Care, Inc. and MEDRAD for travel expenses, accommodation and registration at international conferences.

\section{References}

1. Lassmann M, Pedroli G. Dose optimization in nuclear medicine. Clin Transl Imaging. 2016;4:3. doi:10.1007/s40336-015-0154-7.

2. Le Guludec D, Aigueperse J. Dose optimization: a major challenge for acceptability of nuclear medicine. Clin Transl Imaging. 2016;4: 73. doi:10.1007/s40336-015-0158-3.

3. Andersson M, Mattsson S. Dose management in conventional nuclear medicine imaging and PET. Clin Transl Imaging. 2016;4:21. doi:10.1007/s40336-015-0150-y.

4. Chiesa C, De Sanctis V, Crippa F, Schiavini M, Fraigola CE, Bogni A, et al. Radiation dose to technicians per nuclear medicine procedure: comparison between technetium-99m, gallium-67, and iodine-131 radiotracers and fluorine-18 fluorodeoxyglucose. Eur J Nucl Med. 1997;24(11):1380-9.

5. Del Sole A, Lecchi M, Lucignani G. Variability of $\left[{ }^{18} \mathrm{~F}\right] \mathrm{FDG}$ administered activities among patients undergoing PET examinations: an international multicenter survey. Radiat Prot Dosim. 2016;168(3):337-42. doi:10.1093/rpd/ncv345.

6. Peet DJ, Morton R, Hussein M, Alsafi K, Spyrou N. Radiation protection in fixed PET/CT facilities-design and operation. Br J Radiol. 2012;85(1013):643-6. doi:10.1259/bjr/32969351.

7. Seierstad T, Stranden E, Bjering K, Evensen M, Holt A, Michalsen $\mathrm{HM}$, et al. Doses to nuclear technicians in a dedicated PET/CT centre utilising ${ }^{18} \mathrm{~F}$-fluorodeoxyglucose (FDG). Radiat Prot Dosim. 2007;123(2):246-9.

8. Kulseng CPS, Sandstrøm JC. Effective doses to staff and dose rates emitted from patients undergoing positron emission tomography utilizing ${ }^{18} \mathrm{~F}$-fluorodeoxyglucose. Radiogr Open. 2015;2. https://journals.hioa.no/index.php/radopen/article/view/1526.

9. Walsh C, O'Connor U, O'Reilly G. Eye dose monitoring of PET/ CT workers. Br J Radiol. 2014;87(1042):20140373. doi:10.1259 /bjr.20140373.

10. Kopec R, Budzanowski M, Budzynska A, Czepczynski R, Dziuk $\mathrm{M}$, Sowinski J, et al. On the relationship between whole body, extremity and eye lens doses for medical staff in the preparation and application of radiopharmaceuticals in nuclear medicine. Radiat Meas. 2011;46(11):1295-8.

11. Summers EC, Brown JL, Bownes PJ, Anderson SE. Eye doses to staff in a nuclear medicine department. Nucl Med Commun. 2012;33(5):476-80.

12. Salesses F, Perez P, Maillard AE, Blanchard J, Mallard S, Bordenave L. Effect of dosimeter's position on occupational radiation extremity dose measurement for nuclear medicine workers 
during ${ }^{18}$ F-FDG preparation for PET/CT. EJNMMI Phys. 2016;3(1):16. doi:10.1186/s40658-016-0152-5.

13. Wrzesien M, Napolska K. Investigation of radiation protection of medical staff performing medical diagnostic examinations by using PET/CT technique. J Radiol Prot. 2015;35(1):197-207. doi:10.1088/0952-4746/35/1/197.

14. Pant GS, Sharma SK, Rath GK. Finger doses for staff handling radiopharmaceuticals in nuclear medicine. J Nucl Med Technol. 2006;34:169-73.

15. Wrzesién M, Olszewski J, Jankowski J. Hand exposure to ionising radiation of nuclear medicine workers. Radiat Prot Dosim. 2008;130(3):325-30.

16. Chruscielewski W, Olszewski J, Jankowski J, Cygan M. Hand exposure in nuclear medicine workers. Radiat Prot Dosim. 2002;101(1-4):229-32.

17. Carnicier A, Ginjaume M, Sans-Merce M, Donadille L, Barth I, Vanhavere F. Occupational exposure: with special reference to skin doses in hands and fingers. In: Mattsson S, Hoeschen C, editors. Radiation protection in nuclear medicine. Heidelberg: Springer Verlag; 2013. p. 93-108.

18. Hudzietzová J, Fülöp M, Sabol J, Doležal J. Assessment of the local exposure of skin on hands of nuclear medicine workers handling ${ }^{18}$ F-labelled radiopharmaceuticals: preliminary Czech study. Radiat Prot Dosim. 2015;1-8. doi:10.1093/rpd/ncv441.
19. Mattsson S, Andersson M, Söderberg M. Technological advances in hybrid imaging and impact on dose. Radiat Prot Dosim. 2015;165(1-4):410-5. doi: 10.1093/rpd/ncv024. Erratum in: Radiat Prot Dosim. 2016;168(2):292.

20. Berthold T, Weber B, Buck A. An Automatic 18F-FDG infusion system in clinical PET/CT. Radiological Society of North America 2009 Scientific Assembly and Annual Meeting, November 29 December 4, 2009, Chicago IL

21. Schleipman AR, Gerbaudo VH. Occupational radiation dosimetry assessment using an automated infusion device for positron-emitting radiotracers. J Nucl Med Technol. 2012;40(4):244-8.

22. Sánchez RM, Vano E, Fernández JM, Ginjaume M, Carreras JL. Evaluation of an automated FDG dose infuser to PET-CT patients. Radiat Prot Dosim. 2015;165(1-4):457-60. doi:10.1093 $/ \mathrm{rpd} / \mathrm{ncv} 077$.

23. Lecchi M, Lucignani G, Maioli C, Ignelzi G, Del Sole A. Validation of a new protocol for ${ }^{18} \mathrm{~F}-\mathrm{FDG}$ infusion using an automatic combined dispenser and injector system. Eur J Nucl Med Mol Imaging. 2012;39(11):1720-9. doi:10.1007/s00259012-2174-0.

24. Lucignani G, Del Sole A. Nuclear medicine: what kind of quality would we want if we were the patient? Eur J Nucl Med Mol Imaging. 2010;37(11):2194-2198. 